\title{
An Unusual Dermoid Cyst of the Neck presenting as Mass in the Lateral Neck
}

\author{
PV Pradeep, Rekha Matta
}

\section{ABSTRACT}

Cystic lesions in the neck are common. It is customary to classify them as those arising in the midline and those in the lateral neck. Dermoid cysts are present along the lines of embryonic fusion and hence said to be occurring due to an embryonic accident during the development. Most common locations in the neck are the lateral end of eyebrows and the floor of the mouth in the midline. We present a rare case of dermoid presenting as a mass in the lateral aspect of neck. Our case is unique since even though it was a dermoid cyst, the presentation of the mass was in the upper lateral neck which is very uncommon. A 28-year-old lady presented with a swelling at the junction of the upper one-third and lower two-third of the left sternocleidomastoid muscle. Intraoperatively, the cyst had extension from the lateral aspect of neck along the carotid sheath to the superior mediastinum. Dermoid cysts do present occasionally as lateral neck mass and must be kept in the differential diagnosis. Even though characteristic radiological and histopathological features make the diagnosis of dermoid cyst simple yet it may be difficult to diagnose, if present at unusual locations.

Keywords: Dermoid cyst, Lateral neck.

How to cite this article: Pradeep PV, Matta R. An Unusual Dermoid Cyst of the Neck presenting as Mass in the Lateral Neck. World J Endocr Surg 2012;4(1):26-28.

\section{Source of support: Nil}

Conflict of interest: This is to certify that I, Pradeep PV, the author of 'An Unusual Dermoid Cyst of the Neck presenting as Mass in the Lateral Neck' certify that there is no conflict of interest regarding the publication of this manuscript.

\section{INTRODUCTION}

Cystic lesions in the neck are common. It is customary to classify them as those arising in the midline and those in the lateral neck. The common midline cystic masses in the neck are thyroglossal cyst, thyroid cyst, sublingual dermoid, suprasternal space abscess, subhyoid bursitis, Ludwig's angina. Cystic hygromas, branchial cleft cysts, bronchogenic cysts, laryngocele, sternomastoid tumors are having lateral neck location. ${ }^{1}$ Among the dermoid cysts, $7 \%$ are said to be occurring in the head and neck region. ${ }^{2}$ Most common locations are the lateral eyebrow and the floor of the mouth in the midline. Dermoid cysts are present along the lines of embryonic fusion and hence said to occur due to an embryonic accident during the development, where in the epithelial rests become enclaved at the fusion lines. We present a rare case of dermoid presenting in the lateral aspect of neck (Fig. 1A).

\section{CASE REPORT}

Prior institutional ethical committee approval was obtained. A 28-year-old lady presented with a swelling in the upper part of the left side of neck of 4 months duration. There was history of pain initially which subsided after a course of antibiotics. Figure 1 shows the cystic mass at the junction of the upper one-third and lower two-third of the sternocleidomastoid muscle and was extending deep to the muscle to the lower neck. Contrast enhanced CT scan revealed $6.8 \times 5.1 \mathrm{~cm}$ mass extending along the carotid sheath on the left from the greater cornu of the hyoid to the sternoclavicular joint (Fig. 1B). The internal jugular vein and common carotid artery were displaced posteromedially and trachea to the right side.

Intraoperatively, it was noticed that the cystic mass with a well-defined thick cyst wall was extending from the region of presentation in the lateral neck along the carotid sheath toward the midline. In the suprasternal notch region, the mass was extending to the superior mediastinum after passing anterior to the trachea (Figs $2 \mathrm{~A}$ and $\mathrm{B}$ ). The left lobe of the thyroid was medial to the cyst wall and separate from it. The lower end of the cyst was adherent to the brachiocephalic vein on the right side. The left recurrent laryngeal nerve was adherent to the cyst wall in the neck. Cyst was excised in toto preserving the brachiocephalic vein and the recurrent nerve. Figure 2C shows the excised cyst, Figure 2D the cut open specimen filled with cheesy material and Figure 2E shows the cyst wall. Histopathology revealed dermoid cyst.

\section{DISCUSSION}

Swellings in the neck region are classified as midline/lateral neck swellings. They may also be classified as solid/cystic masses. This is primarily for diagnostic purposes since each of these masses have characteristic locations in the neck. Dermoid cysts are present along the lines of embryonic fusion and, in the neck, they are seen in the midline. Dermoid cysts are ectoderm-lined inclusion cysts. It contains squamous epithelium, hair follicles, sebaceous and sweat gland. The cause of dermoid cyst is the failure of surface ectoderm to separate from underlying structures resulting is sequestration of surface ectoderm. In the lateral neck, the common lesions are lymphadenitis, cystic hygromas, branchial cleft cysts, bronchogenic cysts, laryngocele, etc. 
Our case is unique since even though it was a dermoid cyst, the presentation of the mass was in the upper lateral neck which is very uncommon (see Fig. 1). Second branchial cleft cyst is an important differential diagnosis in our case because of the identical location in the neck.
Dermoid and epidermoid cysts differ in the fact that the former also contains skin appendages like sebaceous and sweat glands. ${ }^{2}$ Both these lesions are lined by squamous epithelium. Both these have cheesy keratinaceous material within it. Dermoid cysts present in
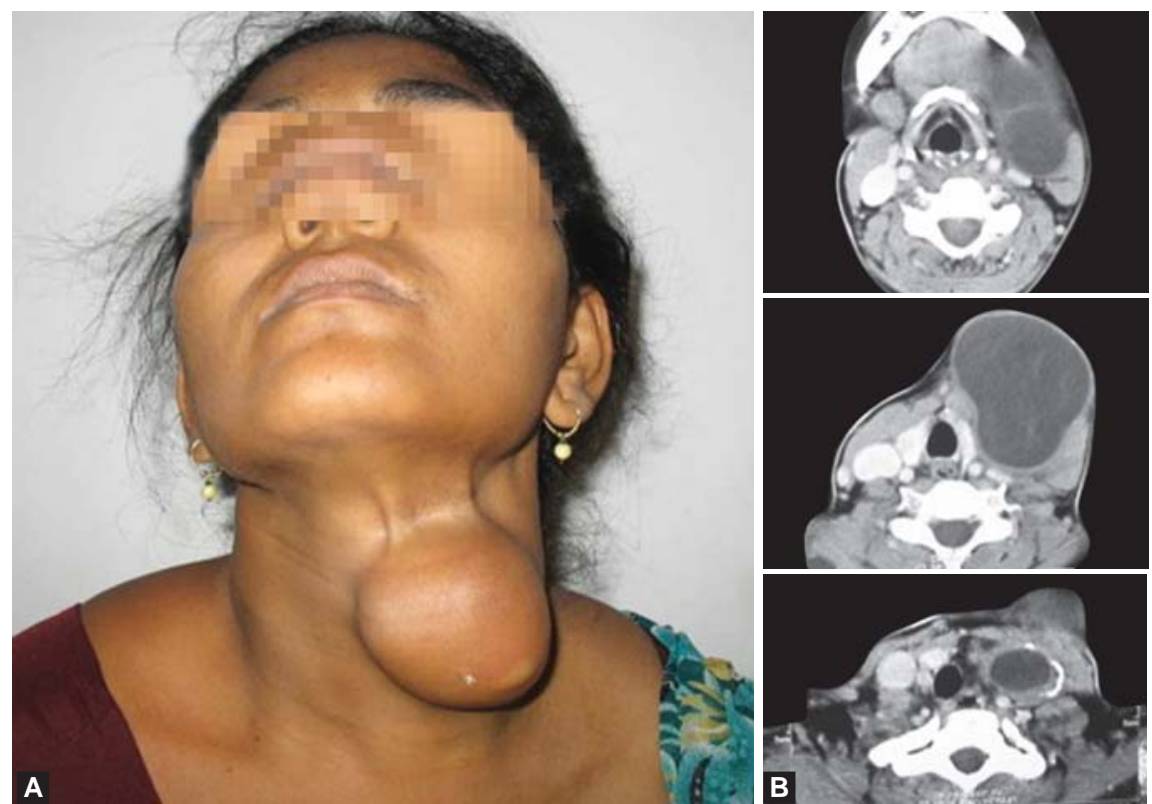

Figs 1A and B: (A) The initial presentation of the dermoid in the lateral neck, (B) CT scan with hypoattenuating mass and calcifications
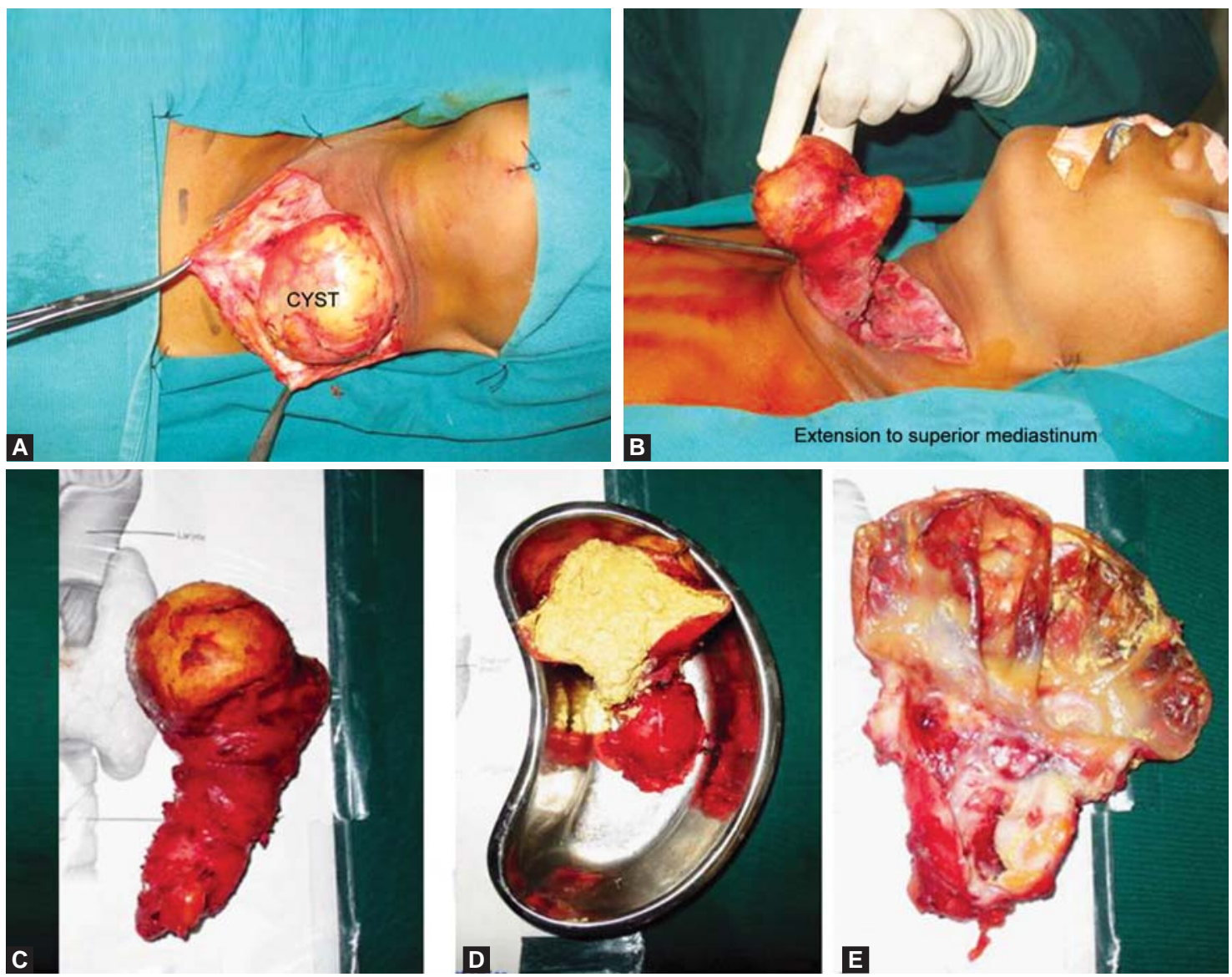

Figs 2A to $\mathrm{E}$ : (A and B) Intraoperative pictures revealing the cyst with extension to the mediastinum, (C) the excised mass, (D) the cheesy material inside, (E) the cyst wall 
the 2nd and 3rd decades of life. ${ }^{2}$ Most common clinical appearance of the dermoid cyst in the neck is in the midline, suprahyoid and suprasternal regions. Pathologically, these are well- encapsulated lesions lined by squamous epithelium that contains skin appendages. ${ }^{3} \mathrm{CT}$ scans typically shows hypo- attenuating lesion (0-18 HU). Sack of marbles appearance is said to be pathognomonic for dermoid cyst. This is due to the coalescence of fat into small nodules. ${ }^{2}$ Our case did not show any such sign even though it was hypoattenuating lesion. Presence of fat-fluid level is also diagnostic of dermoid on CT scan. ${ }^{4}$ Treatment of dermoid cyst is surgical excision. In our case, even though the lesion presented in the upper lateral neck, the lower end of the swelling extended to the midline in the region of superior mediastinum indicating that it had extended from the superior mediastinum upward. Malignant change in dermoid, though rare, has been described in $5 \%$ of cases. ${ }^{5}$

To conclude dermoid cysts do present occasionally as lateral neck mass and must be kept in the differential diagnosis. Even though characteristic radiological and histopathological features make the diagnosis simple yet, it may be difficult to diagnose, if present at unusual locations.

\section{REFERENCES}

1. Hamilton Bailey's demonstrations of physical signs in clinical surgery. Allan Clain (Ed). John Wright and Sons and The English Language Book Society (15th ed) 1973;13:139-53.

2. Koeller KK, Adair CF, Smirniotopoulos JG. Congenital cystic masses of the neck: Radiologic-pathologic correlation. Radiographics 199;19:121-46.

3. Smirniotopoulos JG, Chiechi MV. Teratomas, dermoids and epidermis of the head and neck. Radiographics 1995;15: 1437-55.

4. Rosen D, Wirtschafter A, Rao VM, Wilcox TO Jr. Dermoid cyst of the lateral neck: A case report and literature review. Ear Nose Throat J 1998;72(2):129-32.

5. Som P. Cystic lesions of the neck. Postgrad Radiol 1987;7:211-36.

\section{ABOUT THE AUTHORS}

\section{PV Pradeep (Corresponding Author)}

Associate Professor, Department of Endocrine Surgery Narayana Medical College and Super Speciality Hospital Chinthareddy Palem, Nellore, Andhra Pradesh-524002, India Phone: +91-861-2308944, +91-949-0492876, Fax: +91-861-2317753 e-mail: pradeepputhenveetil@gmail.com

\section{Rekha Matta}

Associate Professor, Department of Cardiothoracic Surgery Narayana Medical College and Super Speciality Hospital Chinthareddy Palem, Nellore, Andhra Pradesh, India 